\title{
FORMULATION OF VALUE ADDED NUTRITIOUS VEGETABLE RELISH USING
}

Moringa oleifera

By

Nisansala Chandrasekara

This thesis submitted in partial fulfillment of the requirements for the Degree of Masters of Food Science and Technology, Department of Food Science and Technology,

Faculty of Applied Sciences, University of Sri Jayewardenepura, Sri Lanka 


\section{DECLARATION}

The work described in this thesis was carried out by me at the Department of Food Science \& Technology, University of Sri Jayewardenepura under the guidance \& supervision of Dr. M. A. Jagath Wansapala, Senior Lecturer, Department of Food Science and Technology, University of Sri Jayewardenepura, Mr. Errol Berman, Managing Director of Ceylon 2U Foods (Pvt) Ltd and Mr Sarath Alahakoon Managing Director of country style foods (Pvt) Ltd, Kadawatha, Sri Lanka .

This thesis and any part of this have not been submitted for any other university or to any other institution for another degree / diploma.

$$
\text { 2olorlog!n. }
$$

Date

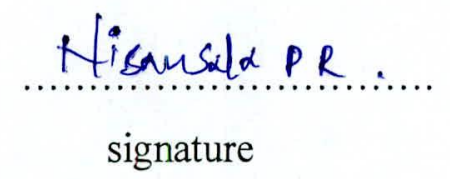


We certify that the above statement made by the candidate is true and that this thesis is suitable for submission to the University for the purpose of evaluation

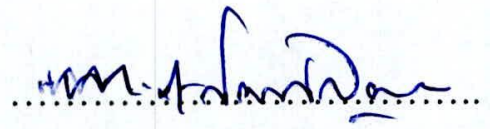

Internal Supervisor

Dr. M. A. Jagath Wansapala,

Senior Lecturer,

Department of Food Science \& Technology,

Faculty of Applied Sciences,

University of Sri Jayewardenepura

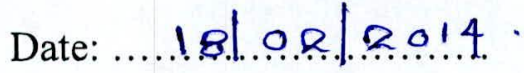

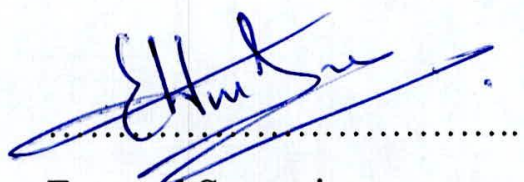

External Supervisor

Mr. Errol Berman

Managing Director

Ceylon 2U Foods (Pvt) Ltd,

144,UDA Industril Estate,kattuwana,

Homagama.

Date: ......ง o. Rol.t.4. 


\title{
AFFECTIONATELY DEDICATED TO
}

\author{
My \\ FATHER, MOTHER \\ AND \\ EVER LOVING TEACHERS
}


TABLE OF CONTENTS ..................................................................................

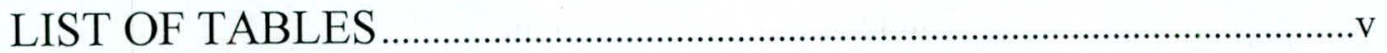

LIST OF FIGURES ....................................................................................... vi

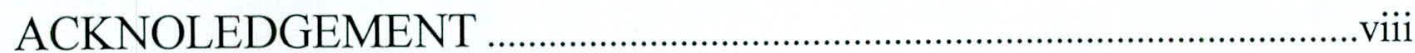

LIST OF ABBEVIATIONS ..........................................................................ix

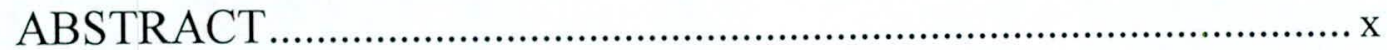

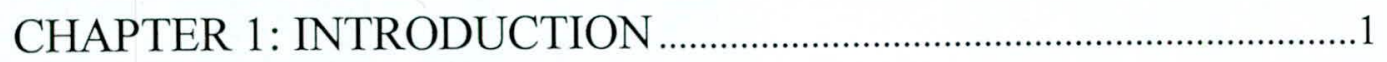

CHAPTER 2: LITERATURE REVIEW ......................................................

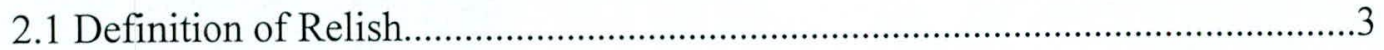

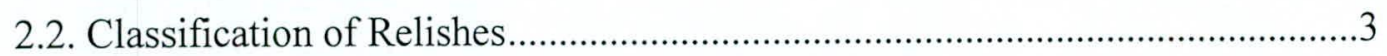

2.3 Different Relish formulations and the composition..............................................

2.3 Locally available vegetables suitable for the Relish.......................................... 8

2.3.1 Moringa oleifera ................................................................... 8

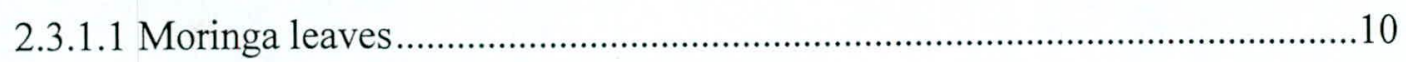

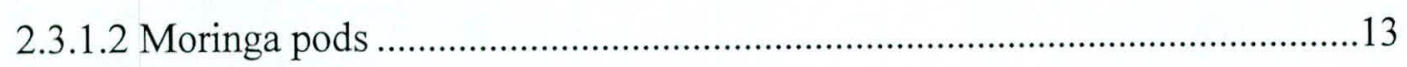

2.3.1.3 Chemical composition of Moringa pods ………………..............................15

2.3.1.4 Nutritional composition of Moringa pods.....................................................15

2.3.1.5 Health benefits of Moringa Pods ...............................................................16

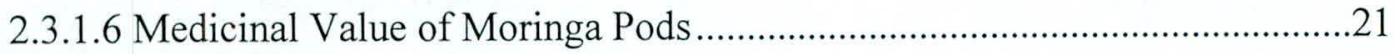

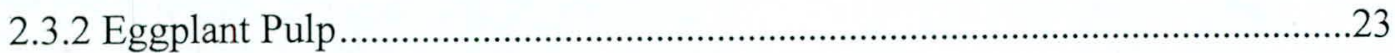

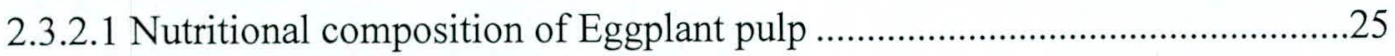

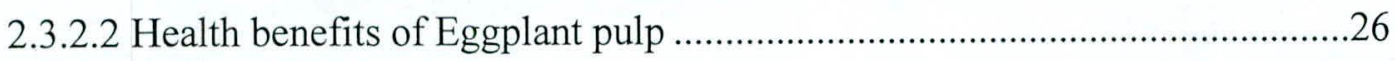

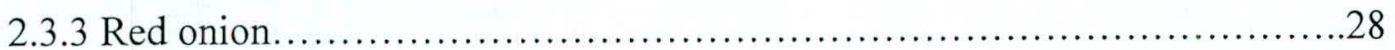

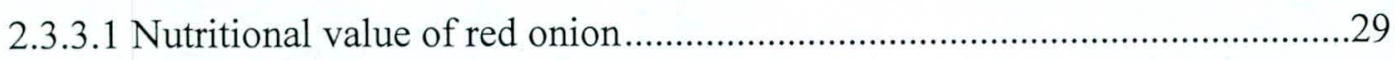

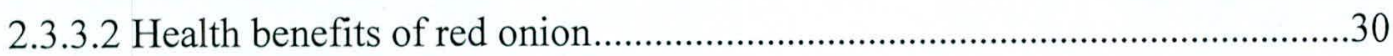

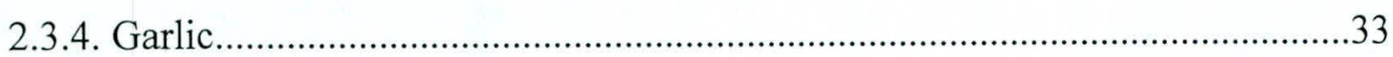

2.3.4.1 Chemical composition of Garlic .................................................................

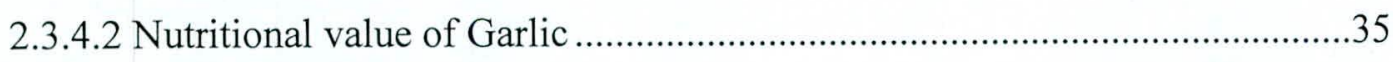

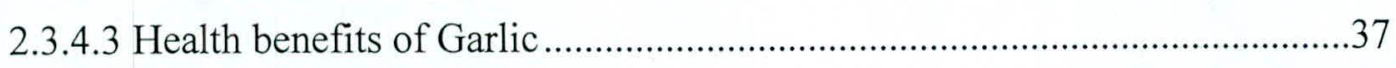

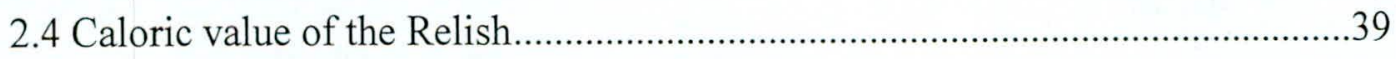

2.5 Packaging information and shelf life evaluation of Relish ...................................40

2.5.1 Factors influencing the shelf life of a product ................................................4

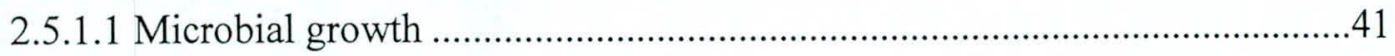




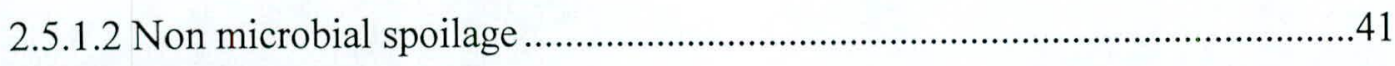

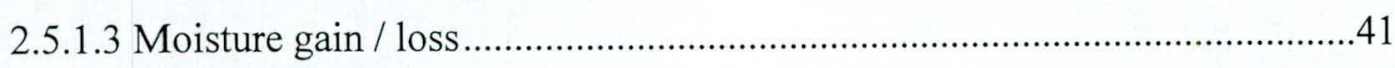

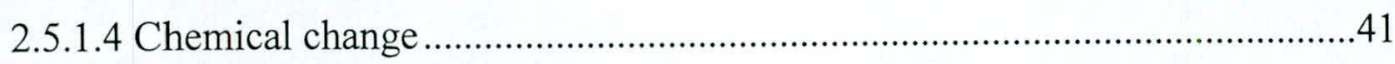

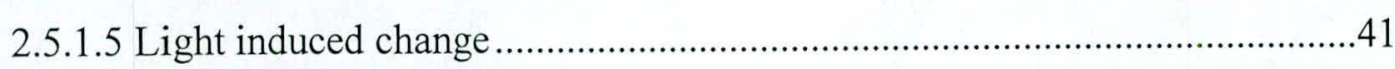

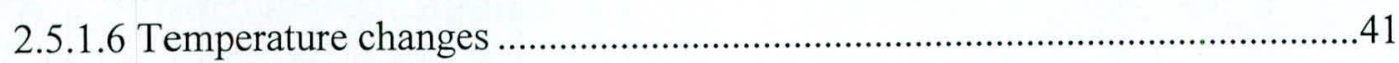

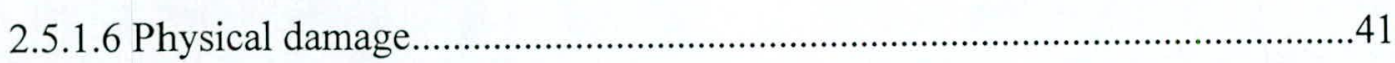

2.5.2 Shelf life evaluation methods......................................................................42

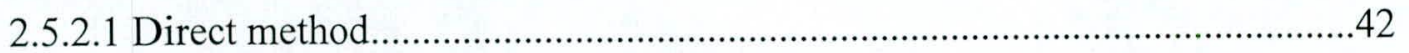

2.5.3 Reasons of the foods to spoil or become unsafe ............................................42

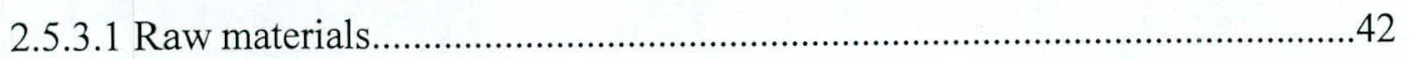

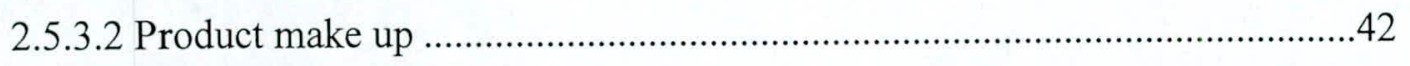

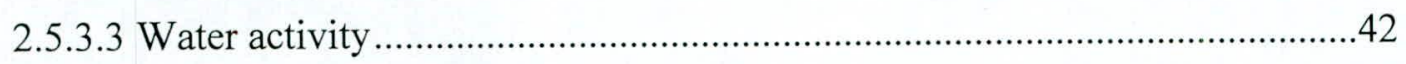

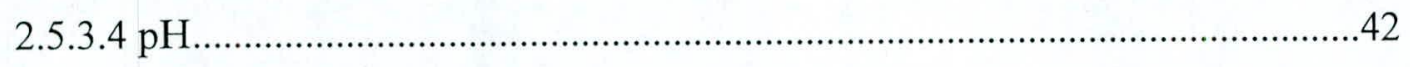

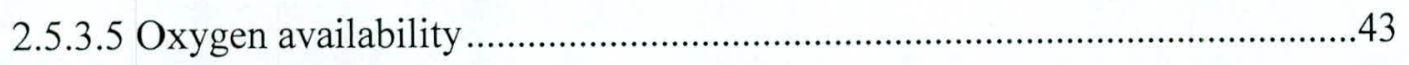

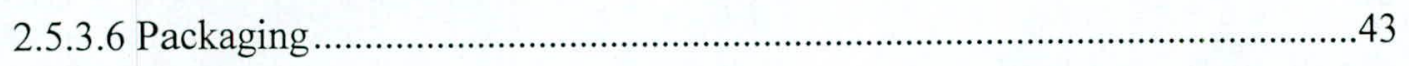

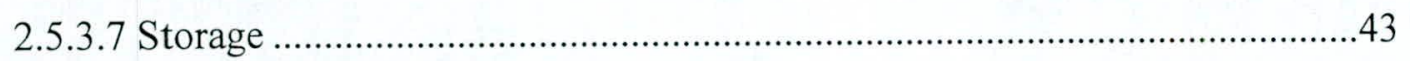

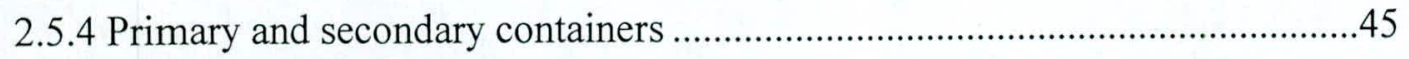

2.5.5 Materials used in Packaging of Food .............................................................45

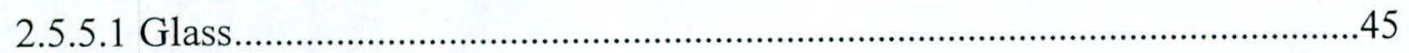

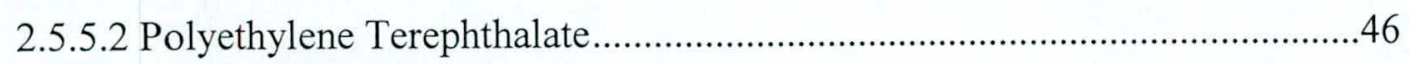

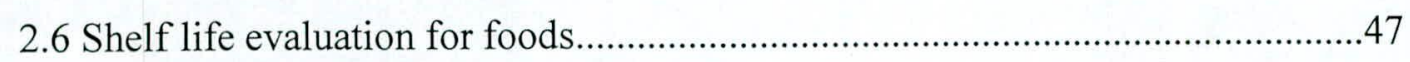

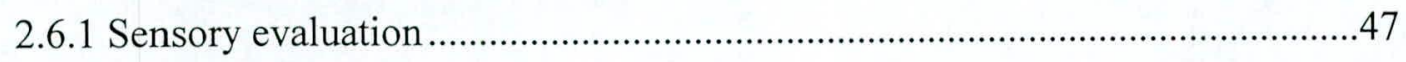

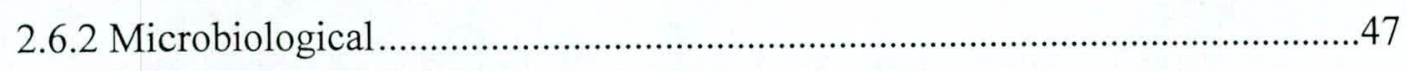

CHAPTER 3: MATERIALS AND METHODS.........................................48

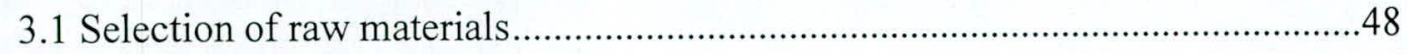

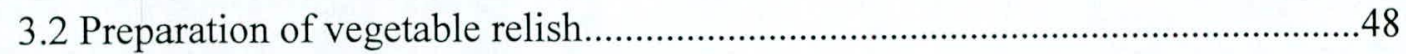

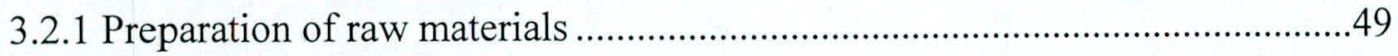

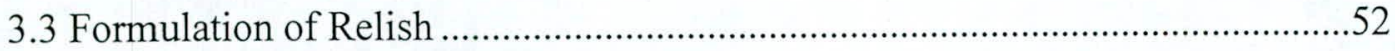

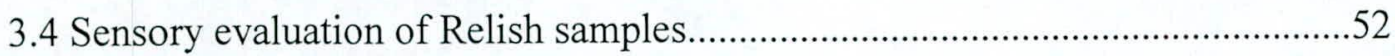

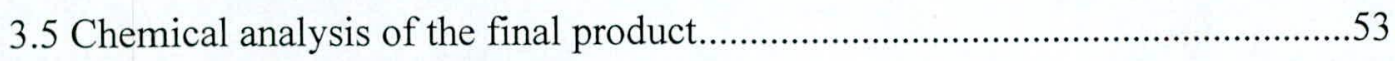

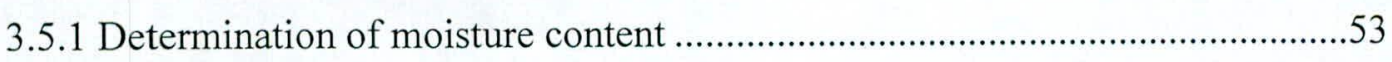

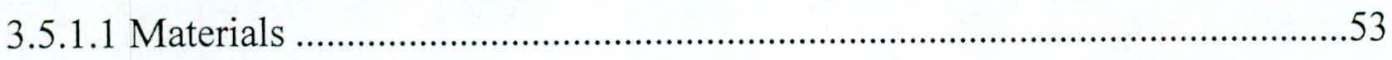

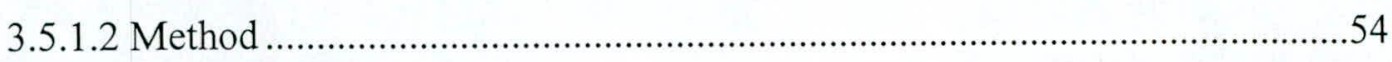

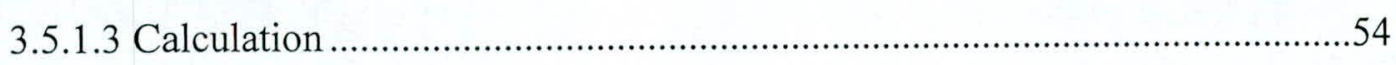




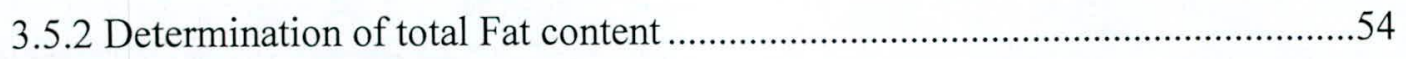

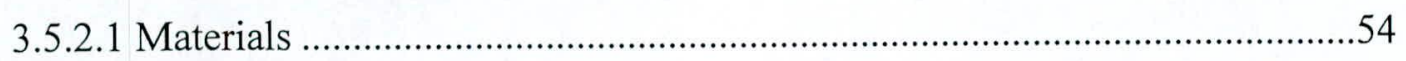

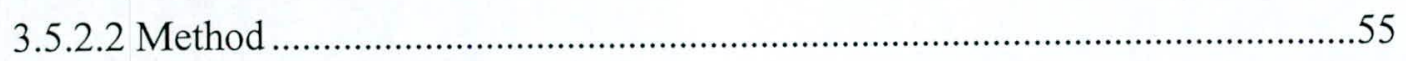

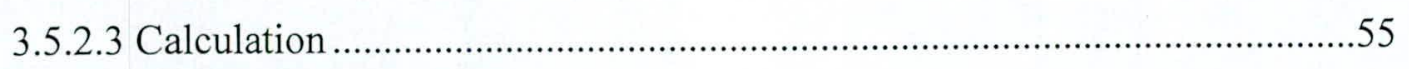

3.5.3 Determination of crude protein content ….....................................................56

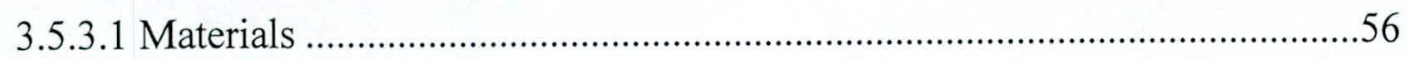

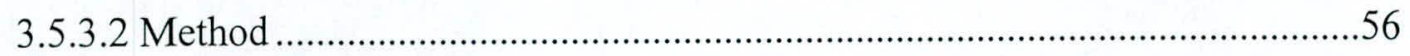

3.5.3.2.1 Preparation of Sodium Thiosulphate solution............................................56

3.5.3.2.2 Digestion, distillation and titration ........................................................57

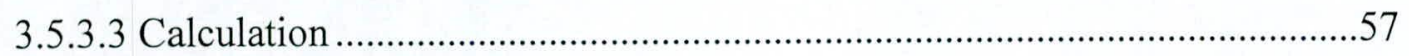

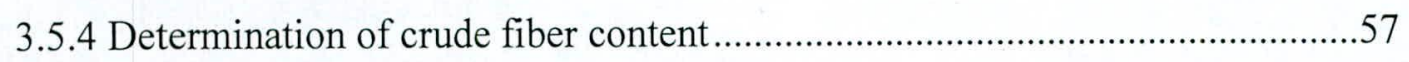

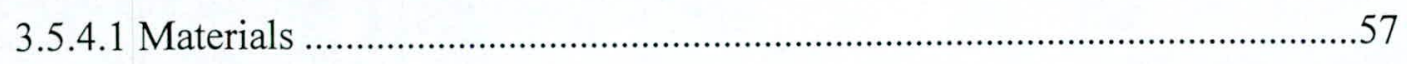

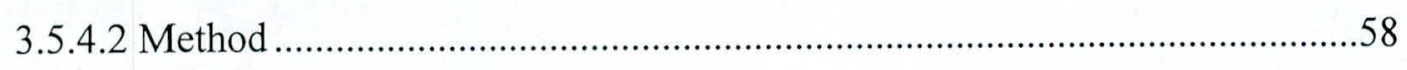

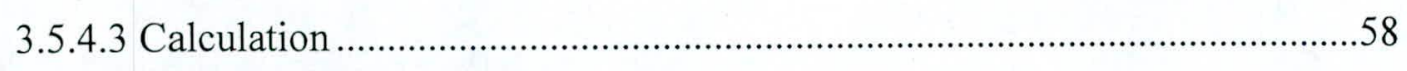

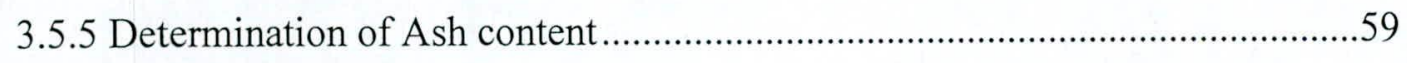

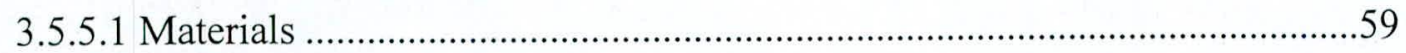

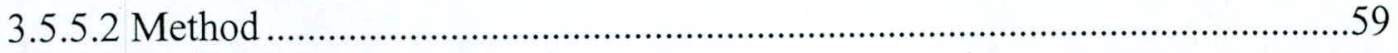

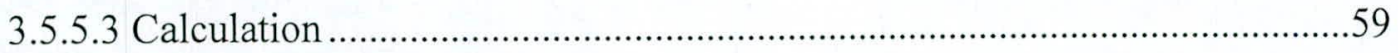

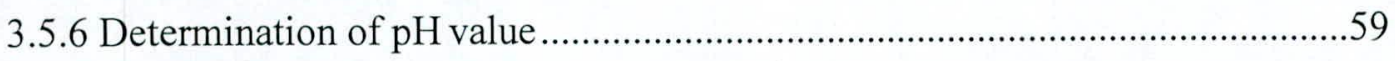

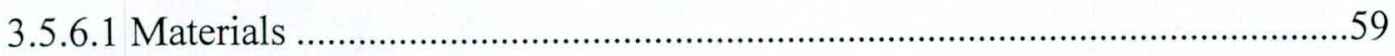

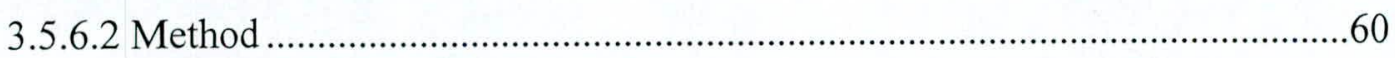

3.5.7 Determination of amount of carbohydrate and caloric content .......................60

3.5.7.1 Determination of carbohydrate content ...................................................60

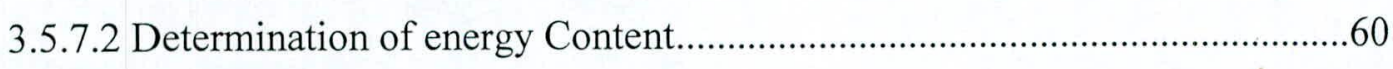

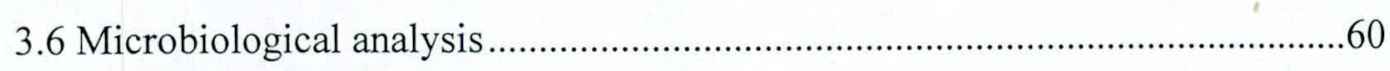

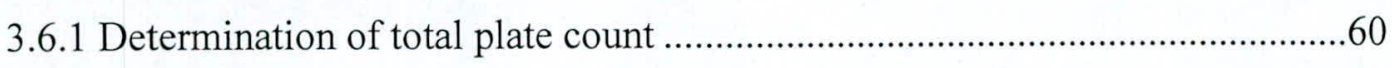

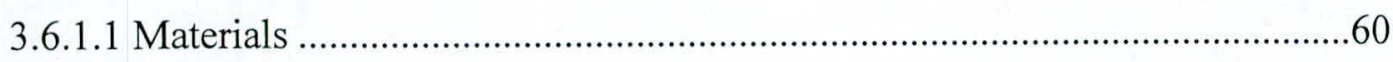

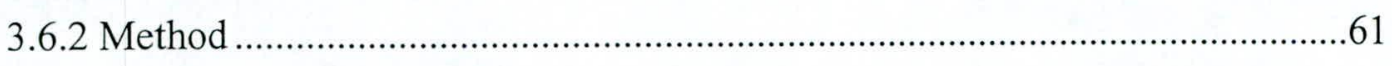

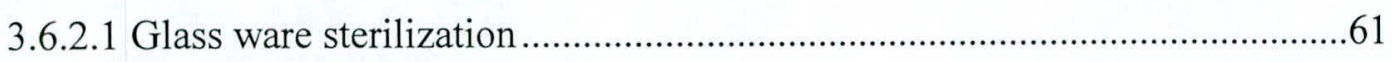

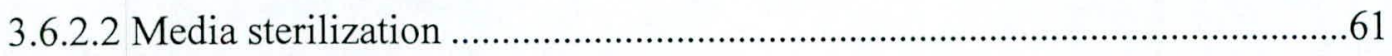

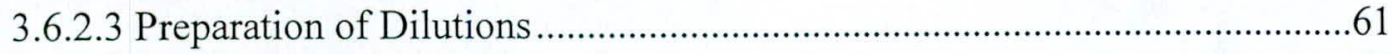

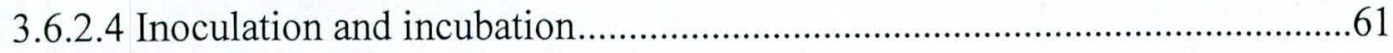

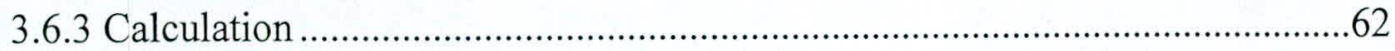

3.6.2 Determination of Yeast, mould and bacteria ................................................62 


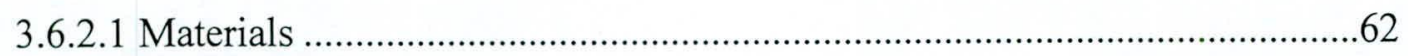

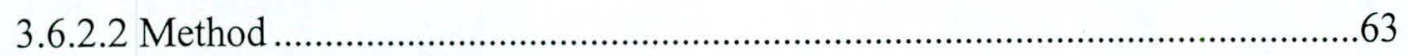

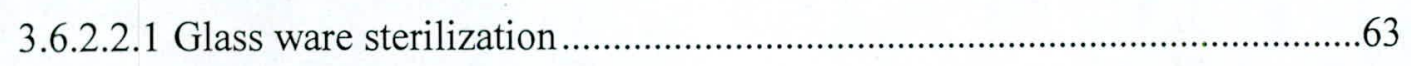

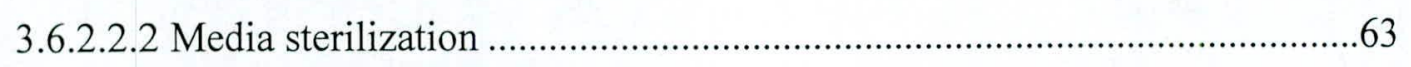

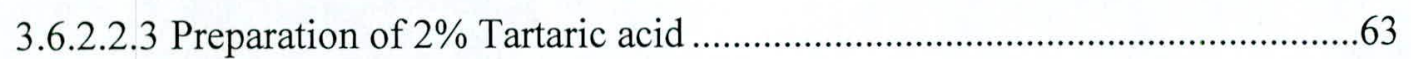

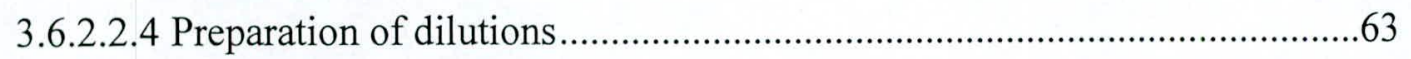

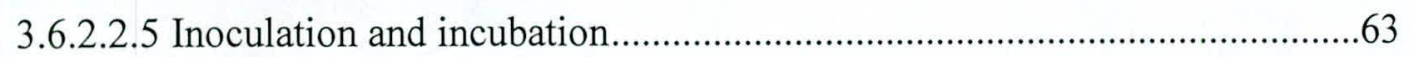

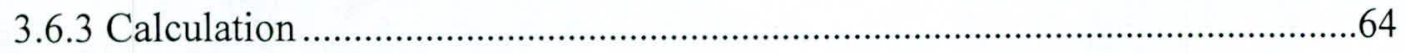

3.7 Selection of suitable package for the final product.............................................64

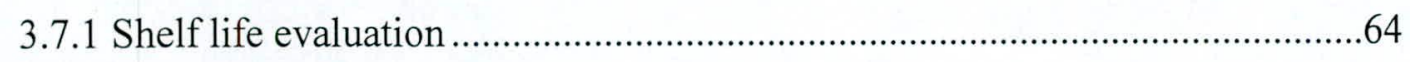

CHAPTER 4: RESULTS AND DISCUSSION ............................................66

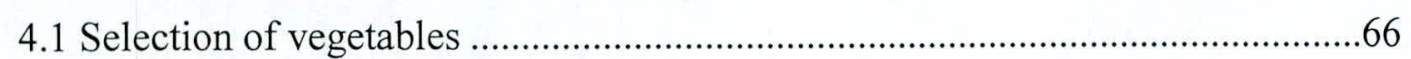

4.2 Selection of formula for development ............................................................6

4.2.1 Results of the sensory evaluation....................................................................67

4.2.1.1 Colour variation in samples ...................................................................69

4.2.1.2 Taste variation in samples......................................................................

4.2.1.3 Flavour variation in samples..............................................................

4.2.1.4 After taste variation in samples.............................................................72

4.2.1.5 Variation of overall acceptability in samples.................................................73

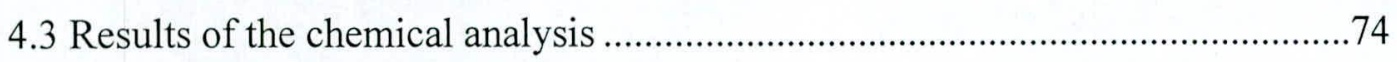

4.4 Results of microbiological analysis .................................................................

4.5 Results for selection of suitable packaging ........................................................77

4.6 Results of the sensory attributes in different packaging ......................................8

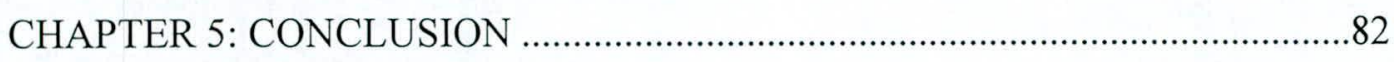

RECOMONDATIONS FOR FURTHER STUDIES .................................................84

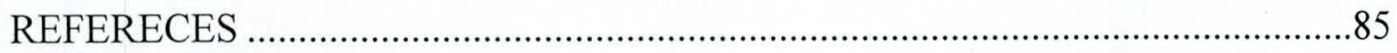

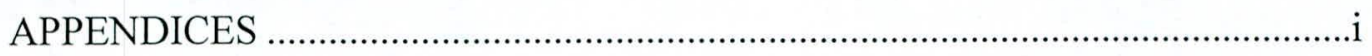




\section{LIST OF TABLES}

2.1: Different Relish formulations and the composition. .5

2.2: Chemical composition and the energy values of the cabbage, green beans and beet root relish 6

2.3: Corn relish recipes .7

2.4: Chemical composition and the energy values corn relish................................8

2.5: Nutritional value of Moringa leaves comparison with common foods ..............13

2.6: Moringa (Drumstick) pods and leaves, raw, Nutritive value per 100 g..............16

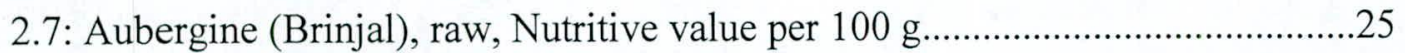

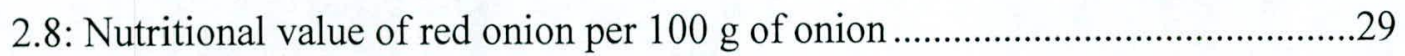

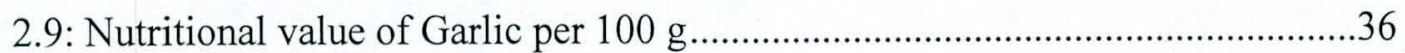

2.10: Energy contribution from the major food ....................................................40

2.11: Standard plate count levels that apply to various ready-to-eat food groups.....47

3.1: Raw materials and equipments used for the preparation . .49

3.2: Formulas developed for final sensory evaluation .52

4.1: Four different samples for the sensory evaluation. .67

4.2: Results of the sensory evaluation . .68

4.3: Chemical analysis results. .74

4.4: Microbial test results of the samples. .77

4.5: Total plate count with different package .78

4.6: Changes of Sensory properties in PET bottle

5.1: Final formulation of the product .82

5.2 Proximate composition of the final product. .83 


\section{LIST OF FIGURES}

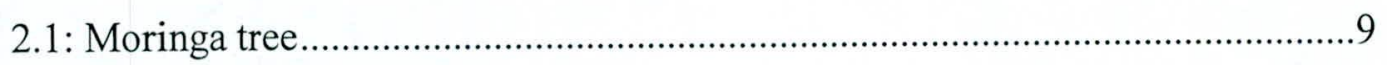

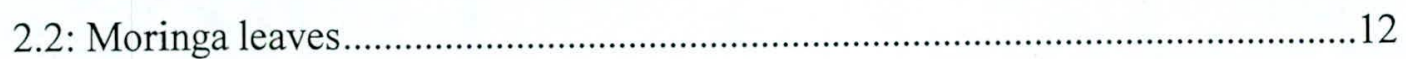

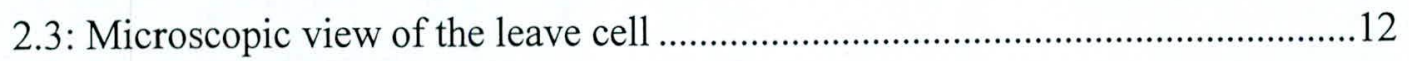

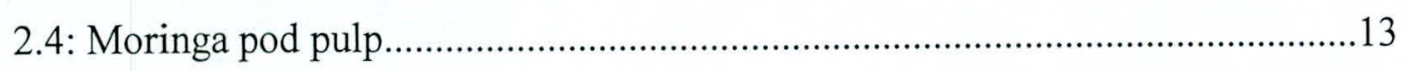

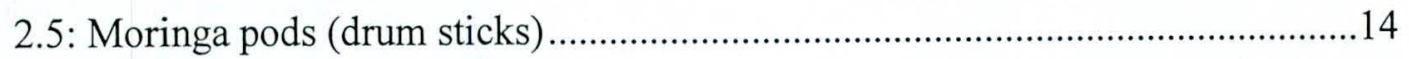

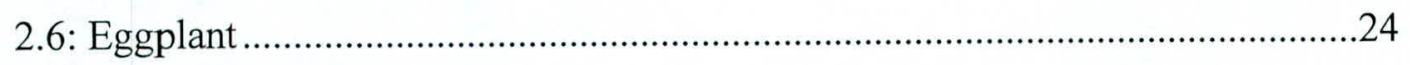

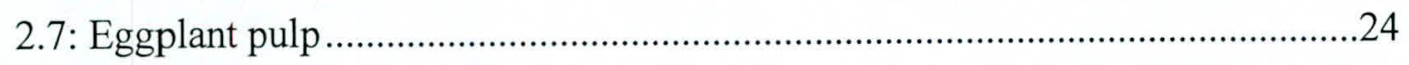

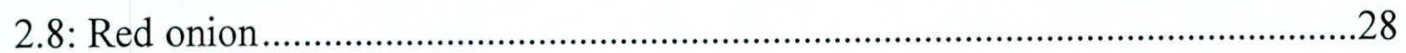

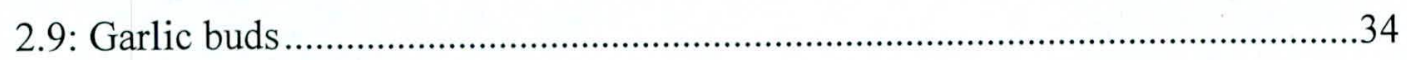

2.10: Allicin, a sulfur-containing compound found in garlic..................................35

3.1: Ingredients used for the preparation .............................................................48

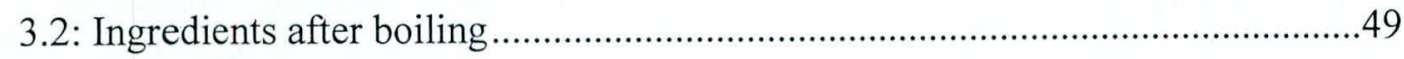

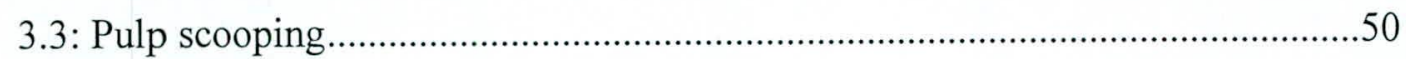

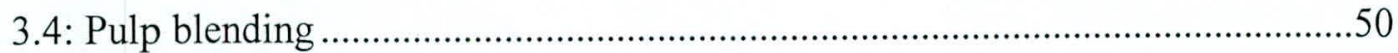

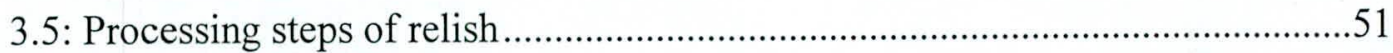

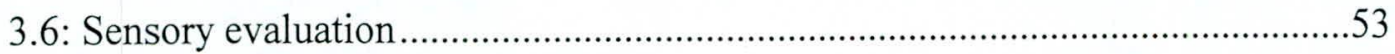

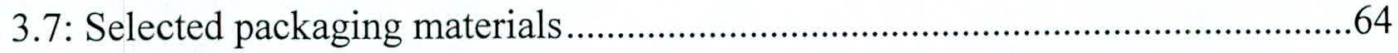

4.1: Descriptive presentation of characteristics of samples with different formulas.67

4.2: Graphical view of sensory attributes of different formulas ...............................68

4.3: Color characteristic variation of vegetable relish samples ...............................69

4.4: Taste characteristic variation of vegetable relish sample ..................................70

4.5: Flavor characteristic variation of vegetable relish sample.................................71

4.6: Variation of after taste in vegetable relish sample.............................................72

4.7: Overall acceptability of vegetable relish sample ...............................................73

4.8: Changes of microbial count in different package within 6 weeks ......................78 
4.9: Changes of sensory attributes with the time in glass bottle

4.10: Changes of sensory attributes with the time in PET bottle ................................80

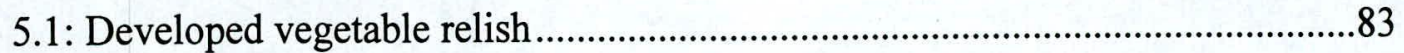




\section{ACKNOWLEDGEMENT}

Foremost, I would like to express my sincere gratitude to my internal supervisor Dr. M. A. Jagath Wansapala, Senior lecturer, Department of Food Science \& Technology, University of Sri Jayewardenepura for the continuous support on my Msc study and research, for his patience, motivation, encouragement enthusiasm, and immense knowledge. His guidance helped me throughout the research works and writing of this thesis.

Besides my advisor, I would like to thank the rest of my thesis committee: Prof. K.K.D.S Ranaweera and Mrs. Rupika Perera and the university staff for their encouragement, insightful comments, and motivational guidance.

I would like to extend my sincere gratitude to Mr. Errol Berman, Managing Director, CEYLON 2U FOODS (PVT) LTD, for granting me leave and for voluble guidance in order to carry out this project.

My sincere thanks also extend to Mr. Sarath Alahakoon, Managing Director, COUNTRY STYLE FOODS (PVT) LTD for offering me the opportunities in their company and leading me towards exciting projects.

I also take this opportunity to thank all my colleagues at the Laboratory and also my friends in Jayewardenepura University who helped me in many ways for my project works.

Last but not the least; I would like to thank my family, my parents for giving birth to me at the first place and supporting me spiritually throughout my life. Words alone cannot express what I owe them for their help and encouragement enabled me to complete this research project. 


\section{LIST OF ABBREVIATIONS}

AOAC- Official Methods of Analysis of Association of Official Analytical Chemists

CFU- Colony Forming Unit

Conc. - Concentrated

Di. - Diluted

FAO- Food and Agricultural Organization

HACCP- Hazard Analysis of Critical Control Point

HCl- Hydrochloric

HDPE- High Density PolyEthylene

PET- PolyethyEthylene Terapthalate

PDA- Potato Dextrose Agar

PPM- Parts Per Million

SLS- Sri Lanka Standards

TPC- Total Plate Count

USDA- United States Department of Agriculture

WHO- World Health Organization

Wt. - Weight 


\section{Formulation of value added nutritious vegetable relish using Moringa oleifera}

\section{By N.P.Chandrasekara}

\section{ABSTRACT}

There are different types of vegetable relishes available in local and export markets. Un leisured life style of modern society today has unintentionally encouraged people to consume fast foods and readymade foods without a second thought of the subsequent impacts on health. Non communicable diseases such as High Blood Pressure, Diabetes mellitus and Cholesterol may cause due to bad food habits. People could not fulfill their nutritional requirement properly due to busy lifestyle. Therefore nutritionally rich, value added and affordable product could play an important role in their life. The objective of the study was to develop a relish with Sri Lankan flavors using locally available vegetable verities and add the economical value to the underutilized Sri Lankan agricultural produces. The findings of the study can be used to improve the healthy life style of a person and minimize the risk of non communicable diseases. In the study: the relish was produced by using moringa flesh, brinjal paste, coconut butter, and red onion, garlic, salt, with a non caloric sweetener. Final formulation of the relish was determined through sensory evaluation. The results of the sensory analysis were analyzed using Kruskal Wallis test in MINITAB software. There were significant difference $(\mathrm{P}=0.05)$ reported for the sensory parameters, for color, flavor, taste, after taste and overall acceptability for the samples and sample 325 showed the best sensory properties when compare with the other samples.

Proximate analysis and shelf life analysis was carried out for the final formulae. The final formulae was consisted $85.66 \%$ moisture, $4.34 \%$ crude protein, $0.51 \%$ total fat, $1.63 \%$ Ash, $4.35 \%$ crude fiber, $3.52 \%$ carbohydrate and $36.03 \mathrm{kcal}$ of calories. The shelf life analysis for the final product was carried out for six weeks using PET and glass containers by testing the sensory attributes and microbial counts. The sensory attributes had not deviated from the initial status and microbiology counts were also within acceptable levels in 6 weeks for the product packed in the glass bottle. Therefore, it can be concluded that the product can be kept for six weeks without any change under the natural environment. Finally the product can be considered as a well balanced and low cost food to fulfill nutritional requirements of people. 


\section{CHAPTER 1}

\section{INTRODUCTION}

A relish is a cooked, pickled or chopped vegetable or fruit food item typically used as a condiment in particular to enhance a staple (Trust, National 2007). It can be smooth or chunky, sweet or savory, hot or mild. A culinary definition is much wider cut fruit or vegetable in acids, with the aid of spices which emphasize food flavour. This is an exceptional quality product made by modern technology which enables keeping the high valuable compounds. They can be served as cold supplements, coating dressing addition. Relishes are eaten in small amounts, along with main dishes to stimulate appetite with its contrast texture and palatable flavour. It is a food that is literally spread, generally with a knife, on to bread, crackers, or other food products. Most of the relishes consist of beet roots, green beans, cabbage, sweet pepper, hot pepper, carrot, onion, garlic, sweet corn celery, cucumber and tomato along with the water, sugar, acids, salt and spices such as cinnamon, cloves, turmeric and mustard seeds (http://en.wikipedia.org/wiki/Relish).

Modern food processing and farming methods have robbed much of the nutritive qualities that make it healthy for bodies. With the advent of big agribusiness combines that reap bountiful crop which are increasingly less and less nutritious for body. The use of pesticides ,fungicides, herbicides and chemical fertilizers have significantly increased crop yields ,but this heavy use of chemicals has produced fruits and vegetables that are not as high in nutrients as they have been historically. The fact that food is less nutritious is made worse by what happens to foods once it leaves the farm. For convenience, safety and marketing purposes, food is subjected to all kinds of preservative that changed the nature of the foods from its natural state. Most companies involving in the food business much more concern about the packaging and marketing except the product nutritional value tends to under nourish the society.

\section{Market opportunity for relish in Sri Lanka.}

Since the phenomenon of globalism and its contribution to a larger availability of formerly location restricted food there has emerged a rather powerful culture centered on food, the latest trends, and the most popular ingredients.

Relish is a relatively new concept to most Sri Lankans. However, it is gaining popularity along with consumers increased exposure to international cuisines and culture. The concept 